Berkala Ilmu Perpustakaan dan Informasi, Vol. 13, No. 1, Juni 2017, Hal. 25-36 DOI: http://10.22146/bip.17054

ISSN 1693-7740 (Print), ISSN 2477-0361 (Online)

Tersedia online di https://jurnal.ugm.ac.id/bip

\title{
PENERAPAN OPEN SCIENCE DI INDONESIA AGAR RISET LEBIH TERBUKA, MUDAH DIAKSES, DAN MENINGKATKAN DAMPAK SAINTIFIK
}

\author{
Dasapta Erwin Irawan ${ }^{1 *}$, Cut Novianti Rachmi ${ }^{2}$, Hendy Irawan ${ }^{1}$, Juneman Abraham ${ }^{3}$, Kustiati Kusno ${ }^{4}$, \\ Mochammad Tanzil Multazam ${ }^{5}$, KeuKeu Kaniawati Rosada ${ }^{6}$, Septriono Hari Nugroho ${ }^{7}$, \\ Galih Kusumah ${ }^{8}$, Defny Holidin', Nurhazman Abdul Aziz ${ }^{8,9}$ \\ ${ }^{1}$ Institut Teknologi Bandung, ${ }^{2}$ University of Sydney, ${ }^{3}$ Bina Nusantara University, \\ ${ }^{4}$ Universitas Tanjungpura, ${ }^{5}$ Universitas Muhammadiyah Sidoarjo, ${ }^{6}$ Universitas Padjadjaran , \\ ${ }^{7}$ Pusat Penelitian Laut Dalam, LIPI, ${ }^{8}$ Universitas Indonesia, ${ }^{9}$ Springer Nature Indonesia \\ Email : dasaptaerwin@gmail.com
}

Naskah diterima: 4 April 2017, direvisi: 29 Mei 2017, disetujui: 12 Juni 2017

\begin{abstract}
ABSTRAK
Gerakan open science telah berkembang pesat dalam lima tahun terakhir. Situasi ini dapat memberikan "angin segar" bagi akademia di Indonesia. Makalah ini ditulis untuk menggambarkan perkembangan konsep dan implementasi open science yang dapat diadopsi untuk meningkatkan dampak saintifik. Kami melakukan review terhadap beberapa makalah, laman lembaga pendana riset, blog open science, dan beberapa diskusi di Twitter. Output riset tidak terbatas pada makalah dalam jurnal bereputasi. Data juga dapat dinyatakan sebagai output terpisah, juga protokol pengelolaan data, serta catatan eksperimen laboratorium. Publikasi berbentuk preprints juga banyak dipilih sebagai alat untuk menyebarkan hasil baru secara luas dan cepat. Post publication peerreview juga telah digunakan dalam sistem review makalah agar lebih terbuka, transparan, dan obyektif. Sistem ini juga memberikan pengakuan kepada para reviewer. Kami juga melihat bertambahnya alternatif indikator sebagai hasil dari penyebaran San Francisco Declaration on Research Assessment (DORA). Berbagai insiatif dan teknologi telah ditambahkan setiap hari untuk membuat ilmu lebih terbuka, transparan, dan inklusif untuk semua. Dengan semua perkembangan itu, maka tidaklah bijak bagi akademia Indonesia untuk bertahan dalam persepsi lama tentang output riset dan indikator dampaknya.
\end{abstract}

Kata kunci: open science, open access, publikasi ilmiah

\section{ABSTRACT}

A significant development of open science movement has been witnessed in the last five years which create impact particularly for Indonesia academia The paper aims to showcase the advancement of open science concept and implementation that can be adopted to increase scientific impact. We conducted a review of literature on peer-reviewed papers, websites of funding agency, open science blogs, and threads on social media (Twitter). We believe the values of research output are not limited to a paper in a high reputation journal. Data is now considered as separate output, as well as, data management protocols, and laboratory notes. Publishing research results as a preprint is also used to disseminate findings.. Post publication peer-review is also added to the reviewing system to add openness, transparency, and objectivity which also add credit to the reviewers. We also see the growth of impact indicators as the results of San Francisco Declaration on Research Assessment (DORA) statutory. More initiatives and technologies have been introduced to make science more open, transparent, and inclusive. Within open science and technology developments Indonesian academics should not rely on the old perception of research outputs and impact indicators.

Key word: open science, open access, scientific publication 


\section{A. PENDAHULUAN}

Riset merupakan salah satu modal utama pengembangan bangsa. Tanpa riset maka ilmu tidak akan berkembang dan pola pikir masyarakatnya pun akan terbelenggu dengan pandangan-pandangan lama.

Hasil riset yang terjamin kualitasnya memuat minimum dua hal, yakni logika koheren yang memadai serta menyajikan bukti-bukti nyata. Keduanya saling melengkapi sebagai kontribusi hasil riset terhadap tubuh pengetahuan. Oleh karena itu, penguasaan terhadap perkembangan substantif bidang ilmu serta metodologi riset mutlak diperlukan seiring dengan kewajiban untuk menyebarkan hasil riset. Dalam hal ini, riset perlu dilihat sebagai sebuah siklus. Hasil sebuah riset mesti dipandang sebagai stimulasi untuk mengawali riset selanjutnya (gaya dorong sentrifugal) serta terus-menerus memperbaiki konstruksi riset itu sendiri (gaya dorong sentripetal).

Siklus riset sesungguhnya merupakan sebuah proses sosial yang terus-menerus mengasah ketajaman logis, metodologis, dan aksiologis riset. Sebagaimana hasil riset yang perlu selalu ditinjau konteksnya guna memperoleh pemahaman yang utuh, proses riset pun tidak terjadi dalam ruang hampa. Proses riset mesti dipandang sebagai sebuah proses historikal yang melibatkan lima hal, yakni peneliti, subjek/objek yang diteliti, komunitas periset, komunitas penerbit hasil riset, serta komunitas penggunanya. Kelima komponen tersebut saling berinteraksi.

Jika begitu, kualitas apakah yang perlu dimiliki oleh para periset dan komunitasnya? Tidak lain adalah jiwa keterbukaan. Jiwa-jiwa yang terbuka secara organik akan menyusun sistemsistem yang terbuka, demokratis, dan kolaboratif.

Makalah ini bertujuan untuk membuka wawasan baru tentang open science (ilmu yang terbuka) yang telah berkembang pesat di beberapa negara.

\section{B. TINJAUAN PUSTAKA \\ 1. Ulasan umum}

Saat ini alur kerja riset mengikuti pola yang selama ini dianut, sejak mencari ide, mengambil data, menganalisis, menginterpretasi, dan melaporkan. Tipikal pola kerja periset yang diamati sebagai berikut: bekerja secara offline, bekerja dengan piranti lunak berbayar dan data format binary, bekerja dengan format binary, bekerja dengan media penyimpanan data off line, bekerja dengan jejaring diseminasi yang terbatas, bekerja dengan jejaring kolaborasi terbatas, bekerja dengan sedikit atau bahkan tanpa umpan balik (feedback), dan bekerja secara sequential atau linear.

\section{Apakah hasil riset anda saat ini telahterbuka dan mudah diakses?}

Kenyataan di sekitar kita yang menunjukkan bahwa sejumlah akademia justru tidak mengupayakan keterbukaan dan aksesibilitas terhadap hasil risetnya, apakah ini sebuah hal yang "counter-intuitive". Pada umumnya setiap orang ingin dirinya bermakna bagi orang lain, dan sebuah kebutuhan eksistensial. Peneliti dapat memenuhi kebutuhan ini dengan cara membagikan hasil penelitiannya sambil berharap bahwa hasil tersebut bermanfaat secara sosial bagi orang lain. Oleh karena itu, hambatan-hambatan yang ada akan keterbukaan dan aksesibilitas hasil riset dapat diatribusikan sebagai faktor literasi dan teknis. Di samping itu, terdapat juga faktor-faktor lain yang kurang teknis, seperti sikap terhadap kritik. Sebuah keterbukaan selalu memuat kerentanan untuk menghadapi kritik, baik itu kritik positif maupun negatif. Demikian pula, sebuah hasil riset yang dibuka kepada publik, terlebih hasil riset yang bersentuhan dengan "hajat hidup orang banyak", sudah barang tentu akan mengundang berbagai reaksi pro-kontra. Peneliti yang kurang siap menghadapi berbagai kritik (terutama yang bernada negatif) atas hasil risetnya akan mengantisipasi hal tersebut dengan menutupi sebagian atau seluruh akses terhadapnya.

Faktor di atas berkaitan dengan kepercayaan diri, utamanya dalam kancah internasional. Tidak jarang kita mendengar bahwa peneliti sendiri tidak percaya diri akan proses riset yang dijalaninya, juga untuk disaksikan presentasinya ketika berkonferensi. Ketidakpercayaan ini akan berimplikasi pula pada ketidakpercayaan diri dalam membuka data dan narasi hasil penelitian seluasluasnya kepada khalayak. Kepuasan atas status hasil risetnya sudah terpublikasi dan dapat digunakan untuk naik jabatan akademik. Atau hanya tertera dalam prosiding abstrak atau, dalam format online full paper (karena desakan dari Kemristekdikti), cukup tersimpan pada sebuah repositori institusi penyelenggara konferensi.

Faktor lainnya berkenaan dengan metodologi yang tidak transparan. Berbagai manipulasi dan penyimpangan terhadap data maupun kepengarangan (authorship) tercatat dilakukan oleh sejumlah "oknum" peneliti, baik di 
dalam maupun di luar negeri, baik peneliti berkaliber tinggi maupun peneliti mula-mula. Terdapat pemeo di kalangan akademia di Indonesia, yaitu "Peneliti boleh salah, tetapi peneliti tidak boleh bohong." Masalahnya, kebohongan itulah yang seringkali terjadi dalam konteks bahasan ini. Sebuah ketidaketisan akan diikuti oleh ketidaketisan yang lain. Sudah barang tentu, peneliti yang tahu persis bahwa praktik tidak etis telah dilakukannya, maka akan menutupi praktik tersebut agar tidak terdeteksi. Peneliti yang demikian tidak begitu bergairah untuk membuat seluruh proses risetnya terbuka dan mudah diakses.

Keyakinan bahwa hasil penelitian seharusnya ekivalen dengan sejumlah kekayaan finansial juga menjadi faktor lainnya yang menghambat keterbukaan dan kemudahan akses. Oleh karena seringkali penelitian melibatkan sumberdaya yang tidak sedikit, peneliti beranggapan bahwa seharusnya hasil penelitiannya mampu menghasilkan uang atau "balik modal". Hambatan ini sudah dicoba dicarikan jalan keluarnya dengan berbagai penghargaan finansial terhadap hasil-hasil riset yang berkualitas. Namun demikian, sebagian peneliti tetap beranggapan, misalnya, bahwa jika orang lain ingin menggunakan instrumen penelitiannya, maka orang lain itu harus membayar jeri-payahnya selama menyusun instrumen tersebut. Gerakan "copyleft" mencoba untuk menantang asumsi tersebut meskipun menemui berbagai benturan, karena asumsi-asumsi tersebut banyak berlindung di balik aturan hukum yang secara popular menganut prinsip "copyright". Gerakan "copyleft" memiliki sebuah spirit yakni jika kita bermurah hati kepada sesama, maka kemurah-hatian yang lebih besar akan datang kepada kita tanpa kita sangka-sangka sumbernya di masa depan. Dunia yang instan dan kapitaslime yang menguasai kehidupan kita dewasa ini tentu saja kurang kompatibel dengan semangat tersebut (Irawan dan Rachmi, 2016d).

\section{Apa sajakah indikator kinerja riset anda saat ini?}

Berikut ini beberapa indikator hasil riset yang selama ini kita kenal: laporan, makalah ilmiah dalam jurnal peer-review, makalah ilmiah dalam seminar/lokakarya, jumlah angka sitasi, dan presentasi poster.

Di luar dari yang telah disebutkan, dalam pemahaman open science, dataset juga merupakan output riset, terpisah dari laporan atau makalah yang berisi analisis. Di samping itu bentuk diseminasi lainnya seperti: rekaman video pengambilan data dan presentasi yang dimuat di media daring (Youtube atau Vimeo contohnya), data mentah yang disebarkan luaskan, versi lebih ringan dari makalah yang ditulis sebagai blog post, kultwit (kumpulan tweet yang membahas tema tertentu), live twit (kumpulan tweet yang secara dikirimkan secara langsung dari lokasi event seminar), pre-print (versi final publikasi sebelum menjalani proses peerreview), dll. Untuk itu memang harus lebih kreatif lagi untuk menekankan pentingnya makalah yang disusun. Pekerjaan tidak berhenti saat makalah telah terbit.

\section{METODE PENELITIAN}

Makalah ini disusun dengan metode ulasan literatur (literature review) dengan makalah dikumpulkan dari beberapa sumber indeks yang bersifat gratis: Google Scholar dan Microsoft Academic, serta media sosial Twitter untuk memantau perkembangan open science dan permasalahan yang terjadi.

\section{HASILDAN PEMBAHASAN}

1. Pendekatan open science

Menurut Situs The Open Science Project open science mengusung tema sebagai berikut:

Transparency: transparansi dalam metode, observasi, dan pengumpulan data;

Public availability and reusability of data: ketersediaan data kepada publik, sehingga dapat digunakan ulang untuk berbagai keperluan;

Public accessibility and transparency of scientific communication: hasil riset disampaikan secara terbuka dan transparan kepada publik;

Using web-based/open source tools to facilitate scientific collaboration: da lam implementasinya, riset menggunakan piranti lunak open source atau web-based untuk menggalang kolaborasi. Definisi berbagai istilah di atas juga dapat dibaca di Tennant and Mounce (2015).

Definisi open science menurut Situs FOSTER Open Science, "Open Science is about extending the principles of openness to the whole research cycle, fostering sharing and collaboration as early as possible thus entailing a systemic change to the way science and research is done." 


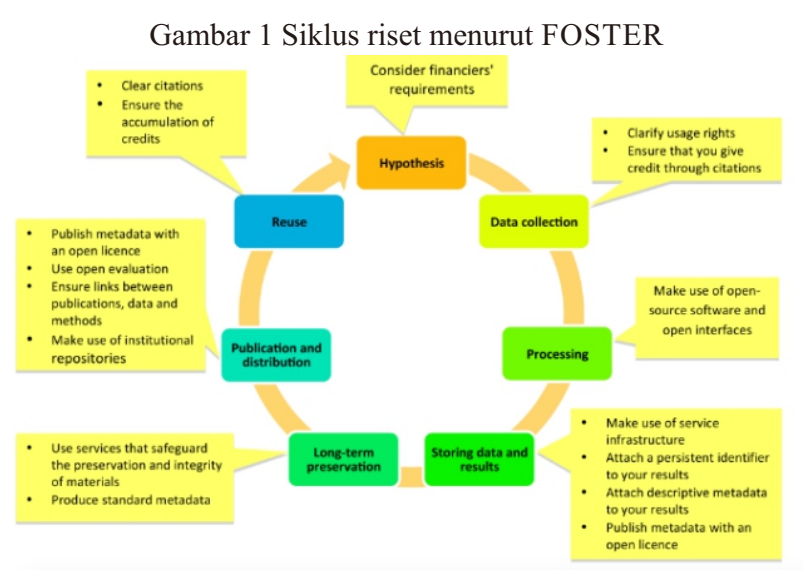

\section{Komponen dan implementasinya}

Dalam implementasinya, open science banyak digambarkan sebagai sarang lebah (bee hive) (Gambar 2). Dapat dilihat bahwa open science meliputi satu rangkaian proses sejak awal riset dimulai hingga akhir saat riset selesai, bahkan bila ditelaah lebih jauh, tidak ada kata selesai. Karena bersifat terbuka, maka hasil dari suatu riset selalu dikembangkan oleh riset yang lain. Termasuk di dalamnya ada komponen periset, komponen pemangku kepentingan (dalam hal ini tertulis sebagai sosial media), dan komponen citizen science. Komponen penting lainnya adalah kurasi, yang merupakan peran dari pustakawan (librarian). Dalam sains modern, posisi mereka bukan hanya sebagai penjaga koleksi buku seperti definisi tradisional, melainkan juga berperan sentral dalam pengelolaan data (data management), dokumentasi (archiving), dan kurasi (curating).

- Open data: menurut Horizon 2020 data riset didefinisikan sebagai:

"Research data refers to information, in particular facts or numbers, collected to be examined and considered as a basis for reasoning, discussion, or calculation. In a research context, examples of data include statistics, results of experiments, measurements, observations resulting from fieldwork, survey results, interview recordings and images. The focus is on research data that is available in digital form. Users can normally access, mine, exploit, reproduce and disseminate openly accessible research datafree of charge."

- Open method dan Open source software

- Open access media

- Diseminasi hasil riset menggunakan open infrastructure
Horizon 2020 sebuah konsep yang diluncurkan oleh Komisi Uni Eropa Dirjen Riset dan Inovasi (European Commission, Directorate-General for Research and Innovation) menyebutkan bahwa data riset juga harus terbuka, termasuk data (Gambar 3)

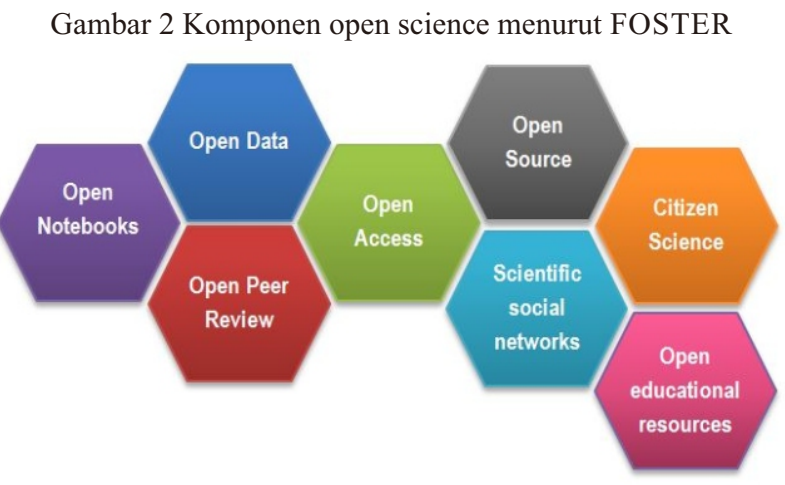

Gambar 3 Konsep akses terbuka ke publikasi dan penelitian ilmiah dalam konteks luas diseminasi dan eksploitasi (Horizon 2020)

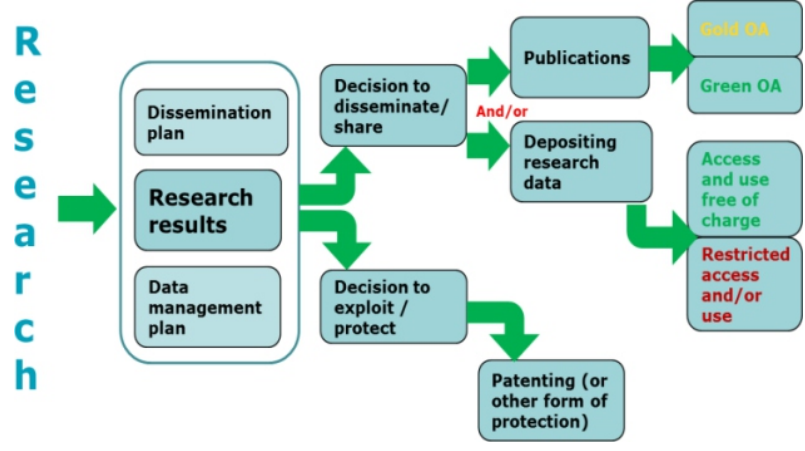

Model ini mempercayai bahwa riset dibangun dari dialog saintifik yang ekstensif dan perbaikan yang berkelanjutan. Ini semua terjadi karena keterbukaan dalam setiap tahapan riset yang dapat membantu dalam memperbaiki kualitas riset. Untuk mengembangkan hasil riset sebelumnya, sehingga mendorong kolaborasi dan menghindari duplikasi yang pada akhirnya dapat meningkatkan efisiensi, mempercepat inovasi, serta melibatkan masyarakat yang idealnya berperan dalam tahap perencanaan, pelaksanaan, dan evaluasinya.

\section{Beberapa modifikasi alur kerja yang diperlukan}

Pembahasan bagian ini dimulai dengan uraian proses sitasi sejak awal, karena sitasi merupakan salah satu indikator dampak yang paling banyak dipakai. Dengan demikian penulis perlu fokus kepada bagaimana agar makalahnya berpeluang lebih besar untuk disitasi oleh penulis lainnya. 


\subsection{Diseminasi makalah dan open peer review}

Sebelum memberikan gambaran alur kerja yang mendukung keterbukaan, perlu ditekankan kembali beberapa hal yang terjadi sebelum dokumen ilmiah apapun yang kita tulis berakhir sebagai sitasi dalam dokumen orang lain. Dari proses itu, modifikasi kerja, yang kami sampaikan di bawah ini akan berkaitan dengan bagaimana agar karya kita diketahui lebih banyak orang dalam waktu yang lebih ringkas, dan bagaimana agar mereka mengetahui bagaimana dokumen kita dapat membantu mereka dalam riset yang sedang dikerjakan.

Berikut ini argumentasi penulis tentang beberapa hal yang perlu terjadi sebelum pada akhirnya dokumen kita dirujuk oleh pembaca. Pertama pelaksanaan riset, dengan bahan baku makalah kita apapun bentuknya.

Selanjutnya proses penulisan dan penerbitan karya ilmiah. Tahapan ini bisa memerlukan waktu enam bulan hingga setahun. Bahkan beberapa orang perlu waktu lebih dari itu hingga karya diterima oleh salah satu jurnal. Hal ini merupakan salah satu kesenjangan waktu yang perlu diatasi dalam siklus saintifik.

Berikutnya tahapan diseminasi, hal ini penting tapi paling sering dilupakan. Diseminasi diperlukan untuk menjamin lebih banyak pihak mengetahui riset kita dan publikasi yang telah dihasilkan. Tahapan ini di luar negeri sering pula disebut science communication. Dalam prakteknya ada banyak cara, mengunggahnya secara daring di repositori terbuka, membuat newsletter berisi daftar publikasi, hingga aktif menyebarkannya di media sosial.

Output dari diseminasi berupa karya kita ditemukan oleh pihak lain untuk dibaca dan dievaluasi. Evaluasi yang pertama kali dilakukan dengan cara apakah makalah kita relevan topiknya dengan rise yang mereka lakukan.

Satu hal lagi yang perlu diperhatikan bahwa sitasi memiliki unsur subyektif. Saat pembaca dihadapkan kepada dua makalah yang topiknya sama, maka ia akan memilih makalah yang lebih mudah dipahami, lebih bagus gambarnya, atau memiliki referensi yang lebih lengkap. Karena hal inilah, para peneliti perlu terus-menerus mengasah kemampuannya dalam menulis, terutama dalam bahasa Inggris.
Sitasi juga tidak akan muncul secara seketika (instant) dalam waktu yang pendek. Rata-rata sitasi akan mulai bergerak naik dan mencapai jumlah maksimal pada tahun ke-3 (Amin and Mabe, 2000 dan Adler et al., 2009), sejak waktu publikasi (lihat Gambar 4 dan Gambar 5). Angka ini merupakan ratarata dari berbagai media dan mestinya tidak berlaku secara universal. Dengan kata lain, para penulis harus memaksimalkan diseminasi makalahnya sejak terbit hingga tahun ke-3 atau ke-4 untuk mencapai jumlah sitasi maksimal, kerena pembaca umumnya akan banyak melewatkan makalah yang berusia lebih dari 3 atau 4 tahun yang lalu.

.."Use of the absolute values of impact factors, outside of the context of other journals within the same subject area, is virtually meaningless; journals ranked top in one field may be bottom in another. Extending the use of the journal impact factor from the journal to the authors of the papers in the journal is highly suspect; the error margins can become so high as to make any value meaningless..." (Amin and Mabe, 2000).

Sejalan dengan makin banyak orang mengetahui bahwa makalah itu ada dan kemudian membacanya. Kurva peningkatan dari tahun ke tahun juga tidak naik tajam.

Sebuah blogpost oleh Scott Weingart (2015) yang ditulis tahun 2012 berisi berbagai grafik visualisasi sitasi (Gambar 4 dan Gambar 5) yang diantaranya menyatakan bahwa untuk makalah yang terbit di tahun 2008, bila di tahun 2012 (3 tahun setelahnya) mendapat sitasi kurang dari 6 kali dapat dianggap sebagai makalah dengan dampak rendah (low impact paper). Kembali lagi fakta-fakta ini dapat sebagai ilustrasi, tidak diposisikan sebagai angka eksak yang berlaku pada berbagai bidang ilmu dan pada berbagai zaman. Hal ini tentunya juga ditentukan oleh kualitas makalah secara keseluruhan,dan dua hal yang mendapat perhatian besar dari pembaca yakni ketersediaan data mentah dan kualitas gambar. Makalah yang baik bila visualisasinya berkualitas rendah juga kecil potensinya disitasi, bahkan dibaca, oleh peneliti lainnya.

Beberapa artikel juga menunjukkan bahwa aktivitas riset berbeda-beda dalam kurun waktu tertentu. Pada waktu tertentu bidang A misalnya lebih intensif digarap dibandingkan bidang B, pada waktu yang lain bisa terjadi sebaliknya. Intensitas kegiatan riset ini dapat mendorong peningkatan sitasi pada bidang tersebut(JCQAR, 2008). 


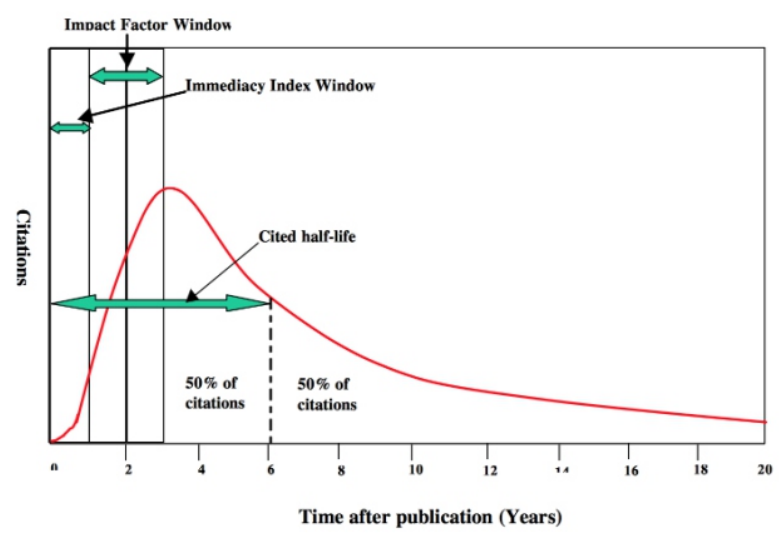

Gambar 4 Kurva sitasi secara umum (Amin and Mabe, 2000)

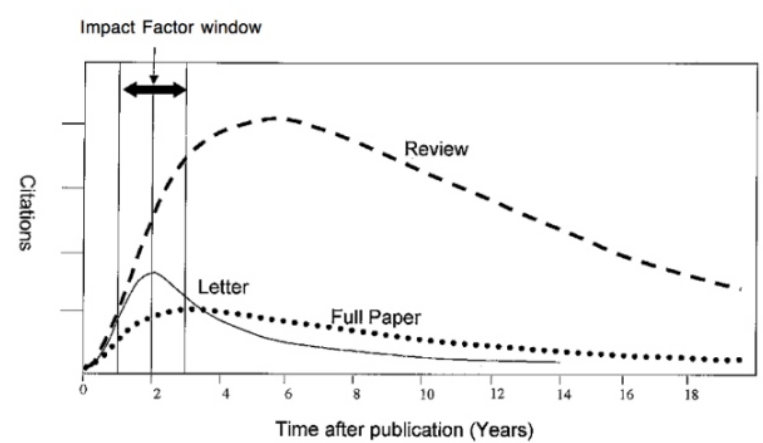

Gambar 5 Kurva sitasi secara umum berdasarkan jenis makalah review, letter, dan full paper (Amin and Mabe, 2003).

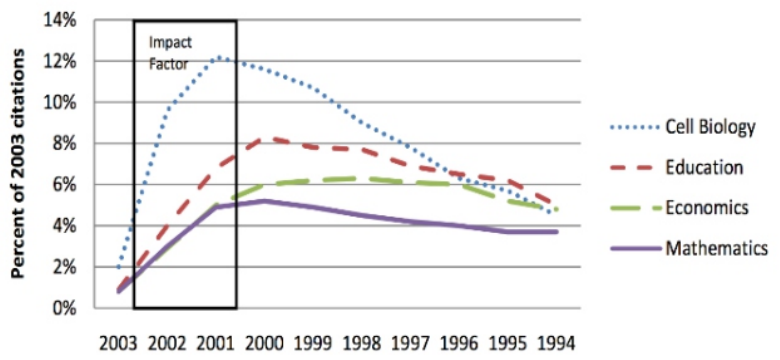

Gambar 6 Kurva sitasi yang dihitung pada tahun 2003, dari makalah yang terbit sejak tahun 1994 (JCQAR, 2008)

Satu komponen yang sering dilupakan yakni peer review. Proses ini sangat penting dalam publikasi karya ilmiah, karena diharapkan dapat memberikan berbagai masukan secara obyektif dan cepat. Selama ini peer review dilakukan dengan sistem blind pre publication peer review. Dalam implementasi open science konsep yang ditawarkan yakni open post publication peer review, dengan:

- Review dilakukan dengan cara terbuka, oleh kedua pihak, reviewer dan penulis dapat saling mengetahui identitas masing-masing. Dengan demikian justru kedua belah pihak dapat lebih berhati-hati dan bekerja atas dasar saling menghormati.
- Hasil review tidak menentukan status makalah apakah diterima untuk dipublikasikan atau tidak. Setiap makalah yang telah memenuhi seleksi administratif meliputi: kesesuaian topik, kesesuaian format, bebas dari kesalahan ketik, serta telah memenuhi kaidah bahasa, langsung tayang secara online dengan status sebagai discussion paper. Selanjutnya para pembaca dapat memberikan berbagai masukan dan koreksi secara terbuka. Kemudian sampai pada batas waktu tertentu, makalah akan diperbaiki oleh penulis untuk memperoleh status peerreviewed. Cara ini diharapkan dapat meningkatkan motivasi peneliti untuk menulis.

\subsection{Gunakan piranti lunak open source}

Untuk menjamin prinsip reproducibility dan replicability, mengirimkan makalah ke media open access adalah baru langkah awal. Selain itu anda perlu juga menggunakan aplikasi atau piranti lunak $(\mathrm{P} / \mathrm{L})$ yang open source. Mengapa? tidak lain agar peneliti lain yang tidak memiliki registrasi atau lisensi piranti lunak seperti yang digunakan, dapat dengan mudah mengunduh $\mathrm{P} / \mathrm{L}$ yang sama.

- Analisa statistik, analisa numerik, visualisasi: Microsoft R Open, RStudio, Shiny Rstudio

- Analisis spasial: QGIS, GRASSGIS, dan aplikasi lainnya yang tergabung dalam komunitas OSGEO.

- Reference manager: Zotero, Mendeley, dll. Mendeley termasuk pengguna terbanyak di Indonesia. Walaupun sebenarnya gratis, tapi Mendeley tidak open source. Pengembangannya akan sangat bergantung kepada tim internalnya.

- Pengolah kata dan tabel: LibreOffice, OpenOffice, atau bagi peneliti bidang tertentu penggunaan LATEX dan Markdown sangat tinggi.

\subsection{Bagikan data dan teknik analisisnya}

Di saat kita masih bersilang-pendapat tentang perlukah data mentah disebarluaskan, di dunia internasional telah bermunculan berbagai kesepakatan multi pihak tentang keterbukaan data (khususnya data penelitian), diantaranya: The Vienna Principles: A Vision for Scholarly Communication in the 21st Century, Budapest Open Access Initiative, Wikidata Initiatives, Open government data principles dan The open govt data book, Dataverse project dan Datacite project. 
Dalam lima organisasi tersebut di atas, data dianggap lebih penting dari makalah ilmiah itu sendiri. Mengapa? Karena bila data tersedia, maka data dapat digunakan ulang (data re-use) untuk dianalisis ulang (reproducible) atau diaplikasikan untuk hal lain (replicable).

Mengapa data termasuk salah satu yang perlu dibagi-pakaikan. Selain karena alasan praktis, bahwa makalah dengan data yang baik, terstruktur, dan lengkap memiliki potensi dirujuk lebih besar, daripada makalah tanpa lampiran data, ada alasan lain. Data merupakan hasil riset yang sangat berharga. Dana telah dikeluarkan untuk mendapatkannya, maka sudah selayaknya data adalah output utama riset, lebih tinggi dibanding analisis atau sintesis terhadapnya (Ekmekcioglu, 2016 ) dan Mounce and Rozenberga (2015).

Terutama pada riset yang dikerjakan atas dana masyarakat (anggaran negara), maka data yang dihasilkan merupakan produk untuk publik (public goods) yang harus dibagikan dengan berbagai cara tanpa mengganggu hak cipta dari tim penyusunnya (RCUK, 2015). Namun tentunya publikasi data harus dilakukan secara cermat, antara lain bisa menyangkut identitas pasien di dunia kedokteran, atau keamanan negara. Beberapa contoh mengenai open data yakni Demographic and Health Survey (DHS), Indonesia Family Life Survey (IFLS), UK Water quality data archive, US open climate data initiatives, Groundwater Open Data System for Bandung Area (Irawan, 2016a dan Irawan et al., 2016e), dan data paper mengenai kualitas air di kawasan Semarang (Irawan and Putranto, 2016b).

Untuk lebih meningkatkan peluang untuk diulang dan direplikasi, maka metode juga perlu diunggah secara lengkap dan transparan. Setiap prosedur dan pengujian perlu dijelaskan secara lengkap, sehingga peneliti lain dapat dengan mudah mengikuti instruksinya. Irawan (2016c), telah memberikan contoh dengan kasus khusus data geosains.

\subsection{Gunakan repositori data terbuka dan registrasi persistent identity (PID)}

Saat ini dunia akademia telah berkembang pesat dengan bermunculannya repositori data online yang gratis tak terbatas (free for unlimited time), gratis terbatas (free for limited time), hingga berbayar. Seandainya kita menemukan makalah yang relevan dengan riset kita, tanpa data yang jelas dan dapat diuji, apakah kita akan menggunakannya sebagai rujukan? Pertanyaan yang sama akan muncul bila ada peneliti lain yang merujuk makalah kita. Untuk menjawab masalah itulah repositori ini dibuat.

Saat ini tercatat sebanyak 3272 repositori hingga hari ini menurut Directory of Open Access Repository (DOAR, 2016) yang terdaftar di Registry of Open Access Repository Mandates and Policy (ROARMAP). Repositori terbuka terbanyak berada di benua Eropa, disusul Asia. Beberapa repositori terbuka dioperasikan oleh universitas terkemuka seperti Johns Hopkins University, Harvard dan MIT. Secara terbuka repositori telah direview secara sistematis. Salah satunya oleh Austin et al. (2015). Bagi yang belum memahami proses manajemen data sebagai output riset, beberapa situs menyediakan informasi yang cukup jelas, misal: Mantra dari University of Edinburgh, University of Minnesota, FOSTER, New England Librarian, di dalamnya terdapat berbagai tutorial mengenai bagaimana data diambil, disiapkan dengan berbagai piranti lunak, diunggah, dan dikelola. Peran pustakawan sangat penting dalam hal ini.

Dari grafik di bawah ini jelaslah bahwa jumlah repositori data daring terus bertambah pesat, ditambah lagi dengan makin banyak layananlayanan gratis yang dapat menumbuhkan semangat membagikan data secara lebih intensif dan lebih luas.

Beberapa yang kami rekomendasikan adalah: Figshare, Zenodo, dan OSF (Open Science Framework). Repositori nomor 1 membolehkan kita menyimpan maksimum 1 giga byte secara gratis, kapasitas lebih besar dari itu dikenakan biaya yang ekonomis, sedangkan repositori no 2 dan 3 menyediakan kapasitas tak terbatas secara gratis dengan ukuran per filenya tidak melebihi lima giga byte (GB).

Atribusi (attribution) sangat penting dalam implementasi open science, karena berhubungan dengan bagaimana cara merujuk karya yang terbuka. Setiap karya harus diyakini jelas penulisnya. Pada akhirnya identitas penulis akan memegang peranan penting. Identitas ganda, atau nama yang sama untuk dua orang yang berbeda sering menjadi kendala. Untuk itu diperlukan identitas yang pasti (persistent $i d / P I D)$ yang terdaftar secara internasional, sistematis, dan terbuka untuk umum, sehingga penulisan rujukan dapat lebih mudah. Salah satu implementasi PID yang berhasil yakni ORCID. 


\subsection{G un a k n m dia sosial untuk mempromosikan karya ilmiah}

Untuk memanfaatkan kekuatan sosial media (medsos) agar lebih menyebarluaskan hasil riset. Media sosial saat tidak hanya digunakan untuk keperluan pergaulan secara umum tetapi juga penyebaran ilmu secara sistematis. Twitter sebagai salah satu media, dinilai sangat potensial karena pola pikir dan ide kita perlu dikemas dalam kurang dari 140 karakter.

Saat ini banyak sekali kerangka medsos, tapi masing-masing memiliki karakter tersendiri (Noorden, 2014). Twitter disebut memiliki karakter saintifik lebih besar dibanding media lainnya. Karakter ini penting untuk dipelajari sebagai bahan memilih medsos mana yang akan dipilih sebagai media diseminasi karya ilmiah.

Gunakan sciencemetrics untuk mengukur dampak publikasi, misalnya Altmetric. Altmetric menggunakan beberapa sumber data, diantaranya dari dokumen kebijakan publik dan media arusutama. Ada lebih dari 2000 media massa dari seluruh dunia, yang menjadi sumber, berbentuk blog, media sosial seperti laman Facebook, Twitter, Google+, LinkedIn, Sina Weibo and Pinterest, online reference manager, post-publication peer-review platforms seperti Publons dan Pubpeer, Wikipedia, Open Sylabus Project, dan Multimedia atau platform lainnya seperti Youtube, Reddit, dan Stackoverflow.

Penggunaan persistent ID sangat berkaitan dengan pengukuran indikator kinerja peneliti/penulis. Agar pengukuran lebih maksimal maka identitas perlu diatur agar tidak terjadi ambiguitas, artinya penggunaan nama harus konsisten. Masalah ini paling banyak terjadi di negara Asia. Untuk bangsa yang memiliki sistem tiga suku kata untuk sebuah nama, maka ini bukanlah masalah. Sebaliknya di Indonesia hal ini menjadi masalah sehari-hari. Penggunaan persistent identity (persistent ID) seperti ORCID dapat banyak membantu.

Pengukuran indikator kinerja peneliti atau penulis juga telah berubah. Indikator-indikator konvensional seperti Impact Factor, Indeks Sitasi, perlu disesuaikan lagi. Berbagai institusi pendidikan dan penelitian saat ini menempatkan pengukuran indikator ini sebagai masalah utama. Data makalah yang disusun oleh seseorang dosen/peneliti merupakan data utama yang dicari. Berbagai profil saintifik telah dibuat, seperti Scopus ID, Researcher ID, Google Scholar Profile, yang ketiganya berbasis kepada perusahaan komersial yang sifatnya tertutup. Saat ini masalah tersebut telah sedikit ada solusinya dengan adanya $O R C I D$, sebuah organisasi nirlaba dan independen yang banyak menjalin kerjasama sinkronisasi akun dengan beberapa profil di atas. Keberadaan ORCID dapat menjadi penghubung untuk menghindari duplikasi identitas dan mengintegrasikan data karya peneliti. Institusi pendidikan, penelitian, ataupun penerbitan yang bekerjasama dengannya dapat menerima sinkronisasi dorongan data dari ORCID bila ada perubahan data karya ilmiah. Material yang diindeks pun saat ini tidak terbatas kepada makalah dalam jurnal ilmiah peer review atau makalah pada seminar, grey literature seperti pre-print atau e-print atau data paper juga dapat dideteksi oleh ORCID.

\section{E. KESIMPULAN}

\section{Dampak implementasi kepada peneliti muda}

Sebagai peneliti muda (young researcher/early career researcher), beberapa output yang menjadi tuntutan, baik di dalam dan luar negeri, meliputi beberapa hal diantaranya jumlah publikasi, jumlah sitasi, jumlah hibah riset yang didapatkan, jumlah sks yang diajarkan, jumlah buku yang diterbitkan dan yang semacamnya. Seluruhnya dapat dibantu dengan mempraktekkan open science. Open science karakter kuncinya yakni keterbukaan (open), berbagi segera (immediate sharing), kolaborasi (collaboration), diseminasi luas (widescope dissemination), dan perbaikan berkelanjutan (sustainable improvement). Dampak yang diharapkan bila kelima hal ini disatukan dengan:

- Pengakuan: ini dimulai dari jumlah view terhadap dokumen yang kita unggah secara online, berkembang kemudian menjadi jumlah pengunduhan (downloads), serta percakapan online yang berlangsung seputar dokumen langsung atau yang topiknya sama. Hal ini dapat diukur dengan mudah menggunakan aplikasi seperti Altmetric atau Impact story.

- Sitasi: paper dengan data yang lengkap, sistematis, dan terbuka memiliki peluang disitasi lebih besar (McKiernan et al., 2016; Eysenbach, 2006; Antelman, 2004; Harnad and Brody, 2004; Adie, 2014). Berdasarkan makalah oleh McKiernan et al. (2016), makalah OA memiliki peluang disitasi lebih besar dibandingkan makalah non-OA.

- Jejaring: Dengan berbicara dalam bahasa yang sama (bahasa data dan keterbukaan) dengan peneliti luar negeri, maka jejaring secara tidak langsung akan terus berkembang. Dengan 
medsos, jejaring ini dapat dibangun lintas negara, lintas budaya, dan lintas usia. Dengan catatan, gunakan medsos yang sesuai dan banyak digunakan oleh komunitas akademia/saintifik.

Salah satu masalah yang dihadapi para peneliti muda yakni kepercayaan diri, berkaitan dengan kekhawatiran mereka menerima komentar dari para seniornya. Senior yang dimaksud di sini yakni senior di tempat kerja, bisa di lembaga pendidikan atau lembaga penelitian. Komentar terhadap makalah para peneliti muda (peer review) sering kali bias serta berisi pernyataan-pernyataan subyektif yang sifatnya menyudutkan. Para peneliti muda ini seringkali menerima kritikan di luar lingkup penelitian yang pada akhirnya dapat menghentikan proses review dan berakhir dengan penolakan makalah. Masalah ini juga mendapat perhatian di luar negeri, selain masalah mengenai kegiatan peer review yang lebih banyak bersifat sukarela, dilakukan di tengah-tengah kesibukan, sehingga hasilnya tidak maksimal (Steel et al., 2016).

Jalan keluar lainnya yang dapat digunakan oleh para peneliti muda untuk dapat menyebarkan ilmunya secara luas dan cepat yakni dengan blogging dan mengunggah preprint (versi pra peerreview). Blog saat ini telah banyak digunakan sebagai media penyebaran ilmu yang seperti halnya bentuk karya ilmiah lainnya dapat dirujuk secara formal. Seperti disampaikan Tennant (2017) dalam blognya, preprint telah diakui sebagai salah satu output riset dan juga dapat disitasi secara formal. Preprint dalam hal ini diposisikan sebagai makalah "mentah" yang selain dapat dirujuk juga dapat dikomentari. Metode ini dipercaya dapat mempercepat proses peer-review formal yang nantinya akan dilalui oleh makalah tersebut.

\section{Dampak implementasi kepada ilmu secara umum}

Dampak positif open science kepada ilmu secara umum hasil dari pengamatan kami dan referensi utama (Tennant et al., 2016):

- open research data: para peneliti dari universitas dan berbagai lembaga penelitian dapat memangkas dana dengan menghindari pengulangan yang tidak perlu;

- open government data: berbagai data yang terbuka dapat mengundang berbagai pihak untuk menganalisis dan melihatnya dari bebagai perspektif (OKSN, 2010; Howard, 2012, Tennison, 2015). Pihak pemerintah akan sangat terbantu dengan adanya data dari pihak lain, sehingga penggunaan dana masyarakat dapat lebih optimal untuk bidang lain;

- open enterprises: bidang usaha komersial akan dapat berkembang bila operasinya dan rencana bisnisnya dibangun atas data yang bebas diakses.

- open society: masyarakat dapat dengan mudah mengakses data-data ilmiah hasil riset, sehingga terhindar dari pseudoscience.

Dampak lainnya secara lebih luas yakni menyebarnya prinsip inklusivitas. Prinsip ini menjadi kunci agar peneliti dari berbagai belahan penjuru dunia dapat saling berkomunikasi secara terbuka dan setara.

Pada masa lalu, peneliti dari negara-negara ketiga, negara berkembang, dan negara-negara yang tidak berbicara dalam bahasa Inggris diposisikan sebagai pengikut dari sejawatnya yang tinggal dan beraktivitas di belahan "barat" yang notabene lebih maju. Dengan prinsip ini, maka peneliti "barat" pun perlu melihat karya peneliti dari balahan "timur" yang kerap kali mengandung nilai keunikan dan orisinalitas tinggi, tapi ditulis dalam bahasa selain Bahasa Inggris.

Beberapa peneliti dan lembaga penggiat open science telah mengakomodir makalah-makalah dalam bahasa selain bahasa Inggris sebagai preprint, misalnya: preprint Authorea (preprint yang diterbitkan oleh platform penulisan makalah online), OSF preprints (preprint yang di-host oleh Lembaga Center for Open Science, serta yang terkini adalah server preprint PaleoArxiv yang juga memberi izin pengiriman naskah tentang paleontologi dalam bahasa non-Inggris. Prinsip ini juga memberikan semangat baru bagi jurnal-jurnal terbitan negara berkembang yang sering dicap sebagai predatory journal dalam berbagai daftar hitam. Kaidah inklusivitas ini digunakan oleh inisiatif Thinkchecksubmit dalam menyebarluaskan panduan mengidentifikasi status jurnal yang baik dan yang patut dipertanyakan.

Responsible Research and Innovation (RRI) digunakan oleh European Commission (EU) sebagai salah satu framework penting dalam visi Horizon 2020. RRI menyampaikan dua hal penting bahwa open science: memperluas pengaruh dan dampak dari penelitian (prinsip yang sama juga disampaikan di Komunitas Why Open Research) dan penting untuk membuat perkembangan ilmu pengetahuan lebih pesat (juga ditekankan oleh McKiernan et al., 2016). 


\section{F. PENUTUP}

Kami hanya akan membuat kesimpulan yang terbuka dalam makalah ini, tetapi dalam penutup ini perkenankan untuk menyampaikan beberapa pesan penting (take home message):

1. Bahwa keterbukaan dalam riset akan memicu lebih banyak dampak positif bagi Indonesia. Kolaborasi dan jejaring akan lebih luas bila setiap hasil riset, termasuk data, dikemas secara terbuka. Data menjadi salah satu output riset, maka sudah selayaknyalah data dapat dipublikasikan secara mandiri, di luar laporan akhir saat riset selesai dikerjakan.

2. Bahwa jalur komunikasi sains dalam era internet lebih dari sekadar email dan telepon, media sosial dengan berbagai positif, negatif dan segmen penggunanya dapat digunakan secara maksimum untuk meningkatkan dampak riset. Jejaring lintas negara, lintas budaya, lintas usia dapat dibangun dengan medsos yang sesuai.

3. Bahwa dampak riset yang selama ini bukan yang utama, misalnya jumlah pembaca, jumlah pengunduh, frekuensi artikel disebarkan di media sosial oleh masyarakat, dapat digunakan sebagai pendamping indikator yang saat ini dinilai yang utama seperti jumlah sitasi.

4. Bahwa sudah selayaknya negara berkembang seperti Indonesia, yang masih memiliki banyak kendala (terutama bahasa), untuk tidak menggunakan satu rujukan dalam menilai kualitas riset atau publikasi. Dalam memilih standar perlu menggunakan lembaga yang independen dan nir laba, bukan perusahaan komersial yang berorientasi profit, sehingga rentan terjadi bias. Bahwa menggunakan lembaga pengindeks yang berafiliasi kepada entitas komersial sebagai indikator kualitas (mencakup kualitas jurnal, seminar, makalah dan kepakaran seseorang) adalah salah, termasuk di dalamnya menggunakan indeks sitasi dari lembaga tersebut, yang jelas-jelas hanya akan menghimpun angka dalam lingkup tertutup. Hal ini hanya akan mengkerdilkan wawasan dan karya kita sendiri.

5. Bahwa institusi pendidikan, penelitian, penerbit dan yang terkait dalam siklus kerjanya bersinergi secara non-profit untuk dapat mempromosikan hasil karya bangsanya sendiri.

6. Bahwa bahasa ilmiah saat ini yakni bahasa Inggris juga standar-standar yang digunakan lebih banyak merujuk kepada benua "barat". Namun demikian, selain upaya kita untuk mendapatkan posisi yang layak dalam dunia internasional, juga jangan dilupakan bahwa kita memiliki kekayaan hayati dan kondisi sosial yang beragam dan unik. Kondisi tersebut harus dapat dimanfaatkan untuk menarik minat baca para peneliti dari negara berbahasa Inggris agar mau membaca karya-karya unik yang ditulis dalam bahasa Indonesia.

7. Bahwa dunia saintifik harus inklusif, untuk itu kita perlu menggalakkan penggunaannya untuk berbagai rujukan baku yang sifatnya mengakomodir kondisi nyata yang ada di Indonesia. Selain menggunakan standar-standar internasional yang sifatnya eksklusif, misal: indeks Scopus, Journal Impact Factor, hendaknya kita juga menggunakan sistem yang telah dibuat oleh lembaga internasional yang mengapresiasi prinsip inklusivitas, misal: indeks DOAJ, Science Open, Altmetric, dll.

Akhir kata, semoga makalah ini dapat menjadi panduan yang bermanfaat bagi semua akademia pada berbagai level, jabatan akademik, juga bagi para pengambil keputusan.

\section{UCAPAN TERIMAKASIH}

Penulis mengucapkan terimakasih kepada beberapa pihak yang telah menginspirasi kami:

1. Dr. Jon Tennant, Graham Steel, Ross Mounce, dan Erin Mckiernan yang telah "mengirimkan" konsep open science dari tanah Eropa ke Bandung melalui tweet-tweet nya;

2. Right to Research Coalition sebagai penyelenggara Open Conference (Opencon) yang melalui media sosial berhasil menyampaikan pesan open science hingga ke belahan bumi yang lain;

3. Peserta Forum Openscience Meeting Group (OMG) yang telah selalu antusias mengikuti setiap pertemuan dan tentunya menyemangati penulis, dan Anggota Forum Dosen Muda RI yang telah banyak memberikan input konstruktif dan yang lebih penting memberikan aura positif dalam setiap komunikasi media sosial;

4. Nobuko Miyairi dari ORCID dan Jolene Esposito dari Center for Open Science yang telah memberikan banyak informasi mengenai konsep persistent ID dan keterbukaan pengelolaan riset;

5. Dan pihak-pihak lain yang tidak dapat kami sebut satu per satu yang baik secara langsung atau tidak langsung menginspirasi kami dalam menghasilkan tulisan ini. 


\section{DAFTAR PUSTAKA}

Adler, R., Ewing, J., and Taylor, P. (2009). Citation statistics: A report from the International Mathematical Union (IMU) in cooperation with the International Council of Industrial and Applied Mathematics (ICIAM) and the Institute of Mathematical Statistics (IMS), Statistical Science, 24(1), 1-14,.

Amin, M. and Mabe, M. (2000). Impact factor: Use and abuse., Retrieved 30 November 2016. http://www.iuma.ulpgc.es/ nunez/doctorado0 910/impactfactor.pdf,

Amin M. dan Mabe M. A. (2003). Impact factors: Use and abuse. Retrieved 30 November 2016. http://www.scielo.org.ar/pdf/medba/v63n4/v6 3n4a11.pdf,

Austin, C., Brown, S., Fong, N., Humphrey, C., Leahey, A., and Webster, P. (2015). Research data repositories: Review of current features, gap analysis, and recommendations for minimum requirements, Journal of IASSIST Quarterly, https://www.rdc-drc.ca/wpcontent/uploads/Review-of-Research-DataRepositories-2015.pdf, Retrieved 17 April 2016.

DOAR (2016). The Directory of Open Access Repositories - Open D A R. http://www.opendoar.org/, Retrieved 17 April 2016.

Ekmekcioglu, C. (2016). Understanding and overcoming challenges to sharing personal and sensitive data. Recon. Figshare. https://dx.doi.org/10.6084/m9.figshare.34667 27.v1 Retrieved: 15 Nov 11, 2016.

FOSTER, Facilitate Open Science Training for European Research. Retrieved: 15 December 2016. https://www.fosteropenscience.eu/

Howard, A. (2012). Data for the public good. Retrieved November 11,2016 http://radar.oreilly.com/2012/02/data-publicgood.html,.

Horizon (2020), Responsible Research and Innovation (RRI). Retrieved: 15 November 2016. https://ec.europa.eu/programmes/ horizon2020/en/h2020-section/responsibleresearch-innovation,.

Irawan, D.E. (2016). Promoting open science: The state of open data initiatives, PAAI Conference 17 Nov 2016, Open Science Framework. Retrieved 15 November 2016. http://doi.org/10.17605/OSF.IO/V64TF.
Irawan, D.E. (2016). Membuat data geosains lebih dapat dibagi (shareable) dan dirujuk (citeable), Bersains, 2(4). https://bersains.files. wordpress.com/2016/04/bersains-vol-2-04data-repository.pdf.

Irawan, D.E. and Putranto, T.T. (2016). Hydrochemical assessment of Semarang area using multivariate statistics: A sample based dataset, Earth Syst. Sci. Data Discuss., doi:10.5194/essd-2016-29

Irawan, D.E. and Rachmi, C.N. (2016). Social media: The more we share the more we learn. Retrieved 15 November 2016. https://www.authorea.com/users/87737/ articles/131825/_show_article.

Irawan, D.E., Suwarman, R., Ulfa, N., Irsyad, M., and Fadli, N. (2016). Groundwater open data system of Bandung city. Open Science Framework. Retrieved November 2016. http://doi.org/10.17605/OSF.IO/TMJXZ,

Joint Committee on Quantitative Assessment of Research (JCQAR) (2008). Citation Statistics, A report from the International Mathematical Union (IMU) in cooperation with the International Council of Industrial and Applied Mathematics (ICIAM) and the Institute of Mathematical Statistics (IMS).Retrieved: 30 November 2016. http://www.mathunion.org/fileadmin/ IMU/Report/CitationStatistics.pdf,

McKiernan, E. (2016). What is open science and why should I care?. figshare. https://dx.doi.org/10.6084/m9.figshare.40334 82.v1. Retrieved: Oct 24, 2016.

Mckiernan, E. (2016). Point of view: How open science helps researchers succeed. Retrieved November 2016. https://elifesciences.org/ content/5/e16800,

Mounce, R. and Rozenberga, D. (2015). The how,when, Where, and Why of Open Data. FOSTER Open Science event for Open Access week 2015. Zenodo. http://doi.org/ 10.5281/zenodo.32436.

Noorden, R.V. (2014). Online collaboration: Scientists and the social network, Nature News Blog. Retrieved 17 April 2016 , http://www.nature.com/news/onlinecollaboration-scientists-and-the-socialnetwork-1.15711,. 
Open Knowledge International (2010). Open data handbook. Retrieved November 11, 2016. http://opendatahandbook.org/guide/en/whyopen-data/,

Open Science and Research Initiatives (2016). Open science and research handbook. Retrieved November 2016. Download Open Science and Research Handbook v.1.0 in pdf format,

RCUK (2015). RCUK common principles on data policy. Retrieved 15 November 2016. http://www.rcuk.ac.uk/research/datapolicy/

Steel G, Price A, Seth B, Biswas R, and Chatterjee P. (2016) Charity is welcome: The international benefits and pitfalls of peer Review. Retrieved 15 December 2016. https://doi.org/ $10.7287 /$ peerj.preprints. $1585 \mathrm{v} 2$.

Tennant, J. (2017). Should we cite preprints? Retrieved 17 May 2017 . http:// fossilsandshit.com/should-we-citepreprints/,.
Tennant, J., \& Mounce, R. (2015). Open research glossary. Figshare. Retrieved November 2016. http://doi.org/10.6084/m9.figshare.1482094.

Tennant, J.P., Waldner, F., Jacques, DC., Masuzzo, P., Collister, LB., Hartgerink, CHJ. (2016). The academic, economic and societal impacts of Open Access: An evidence-based review. $\mathrm{R}$ e $\mathrm{tr}$ i e ve d $\mathrm{N}$ ov e m b e r 20016. https:/f1000research.com/articles/5-632/v1,.

Tennison, J. (2015). Why is open data a public good? https://theodi.org/blog/why-is-open-data-apublic-good,

Weingart, S. (2015). Submission to DH2016, url: http://www.scottbot.net/HIAL.1.htm1, Retrieved 15 November 2016. 